Shamayim: Jurnal Teologi dan Pendidikan Kristiani

Volume 1, Nomor 1, 2020 (1-13)

http://hologos.college/ejournal/index.php/shamayim/index

\title{
Tinjauan Etis Kristen Terhadap Seksualitas Di Kalangan Pemuda-Pemudi Gereja
}

\author{
Alfons Renaldo Tampenawas \\ Sekolah Tinggi Teologi Yerusalem Baru Manado \\ alfonsreenz@gmail.com \\ Veydy Yanto Mangantibe \\ Sekolah Tinggi Teologi Yerusalem Baru Manado \\ vmangantibe90@gmail.com
}

\begin{abstract}
This article discusses the Christian Ethics review of sexuality activities among Christian youth. This article uses a qualitative approach with descriptive methods. The young people are people who are considered as the nation's next generation as well as the church's next generation. However, in the time, these future generations are trapped in a life of promiscuity or fall in free sex (premarital sex). Sexuality is actually a part of creation that wa given by God for humans to develop or continue their offspring, but young people misinterpret sexuality, so they think that sexuality is part of their relationship and can be done even though they are not married.
\end{abstract}

Key words: Christian Ethics, Young, Sexuality

\begin{abstract}
Abstrak
Artikel ini membahas tentang tinjauan Etika Kristen terhadap aktivitas Seksualitas di kalangan pemuda-pemudi Kristen. Artikel ini menggunakan pendekatan Kualitatif dengan metode deskriptif. Pemuda-pemudi adalah orang-orang yang dianggap sebagai generasi penerus bangsa juga sebagai generasi penerus gereja. Akan tetapi dalam perkembangan zaman, para generasi penerus ini terjebak dalam kehidupan pergaulan bebas atau jatuh dalam hubungan seks bebas (seks pranikah). Seksualitas sebenarnya merupakan bagian dari ciptaan yang diberikan Allah bagi manusia untuk berkembang atau meneruskan keturunan, namun seksualitas disalah artikan oleh para kaum muda, sehingga mereka meanggap bahwa seksualitas itu adalah bagian dari pergaulan dan bisa untuk dilakukan walaupun belum menikah.
\end{abstract}

Kata kunci: Etika Kristen, Pemuda-pemudi, Seksualitas. 


\section{Pendahuluan}

Generasi muda pada umur 18 tahun sampai kira-kira 40 tahun adalah generasi yang penting dalam berbagai aspek kehidupan. Usia muda merupakan waktu bagi seseorang untuk berkarya secara produktif dan pada usia ini adalah suatu masa transisi antara hidup untuk belajar tentang jati diri menuju kepada masa seorang pemuda atau pemudi yang akan mengaktualisasikan dirinya dalam berbagai aspek. Seorang pemuda juga dianggap sebagai seseorang yang akan menjadi generasi penerus bangsa. ${ }^{1}$

Seiring berkembangnya zaman, aktivitas seorang pemuda tentunya akan sangat dipengaruhi oleh berbagai kondisi atau konteks kehidupan, baik dalam hal yang positif maupun hal yang negatif. Salah satu hal yang sangat mempengaruhi kehidupan pertumbuhan seorang pemuda ialah pergaulan bebas (seksualitas). Sitorus menyatakan dalam penelitiannya bahwa seorang pemuda yang hamil diluar nikah itu diakibatkan karena masa pacaran yang tidak benar atau dengan bahasa lain ialah pacaran yang tidak sesuai dengan ajaran kristiani. Selanjutnya sitorus memaparkan beberapa faktor yang menjadi penyebab seorang pemudi hamil diluar nikah, yaitu Pertama, Faktor kurangnya perhatian dan pengawasan orang tua, Kedua, Faktor pergaulan bebas, Ketiga, Faktor kurangnya pembentangan/pertahanan diri, Keempat, Faktor tidak mendapatkan Pengetahuan Seksualitas, Kelima, Faktor Teknologi. ${ }^{2}$

Seksualitas adalah sebuah naluri alamiah yang ada dalam setiap diri manusia yang diciptakan oleh Allah bagi manusia untuk berkembang biak dan melanjutkan keturunan. Allah melihat seksualitas itu sungguh amat baik (Kej. 1:28). Bahkan seksualitas itu juga adalah anugerah bagi manusia, karena tanpa seksualitas manusia tidak bisa meneruskan keturunannya. Dalam kekristenan, hubungan seksual hanya diperkenankan ketika sudah menikah. Pernikahan menjadi tempat yang sangat baik dalam mengekspresikan seksualitas. Namun dalam realita yang ada, pemuda-pemudi telah berhubungan seksual diluar pernikahan.

Penelitian yang dilakukan oleh Reckitt Benckiser Indonesia lewat alat kontrasepsi Durex terhadap 500 remaja di lima kota besar di Indoensia menemukan, 33 persen remaja pernah melakukan hubungan seks penetrasi. Dari hasil tersebut, 58 persennya melakukan penetrasi di usia 18 sampai 20 tahun. Selain itu, para peserta survey ini adalah mereka yang belum menikah. ${ }^{3}$

Pergaulan bebas dalam hal ini ialah "seks bebas" memang menjadi ancaman secara tidak langsung bagi kehidupan pemuda-pemudi. Salah menempatkan diri untuk bergaul akan berdampak buruk bagi kehidupan pertumbuhan baik secara fisik maupun secara

\footnotetext{
${ }^{1}$ Andi Irawan, “Aktivitas Anak-Anak Dan Pemuda Dalam Penggunaan Internet," Cyber Security dan Forensik Digital (2018): 52.

${ }^{2}$ Theresia Tiodora Sitorus, "Implikasi Pembinaan Pemuda Gereja Atas Faktor-Faktor Penyebab Kasus Hamil Di Luar Nikah,” Evangelikal: Jurnal Teologi Injili dan Pembinaan Warga Jemaat (2020): 196197.

${ }^{3}$ https://www.liputan6.com/health/read/4016841/riset-33-persen-remaja-indonesia-lakukan-hubunganseks-penetrasi-sebelum-nikah\#
} 
emosional bahkan juga sosial. Kurangnya pehaman yang benar terhadp dunia seksualitas, menjadi faktor juga bagi seorang pemuda melakukan kegiatan "seks bebas".

Hasil penelitian yang dilakukan oleh Astuti, menyatakan bahwa salah satu faktor yang mengakibatkan terjadinya seks bebas ialah pengetahuan terhadap seksualitas yang kurang baik. ${ }^{4}$ Sedangkan, hasil penelitian dari Tasidjawa, Korompis, Tucunan, menyatakan bahwa terjadinya seks pranikah karena pengetahuan terhadap alat reproduksi yang kurang baik. $^{5}$

Dalam penelitian ini, penulis meneliti pemuda-pemudi Kristen yang ada di GMIM Paulus TWM, Manado Sulawesi Utara. Dalam pengamatan dan penelitian, penulis menekuman bahwa pergaulan menjadi suatu faktor yang menyebabkan mereka melakukan hubungan seks pranikah. Oleh sebab itu perlu diteliti pemahaman mengenai seksualitas secara etika Kristen. Maka untuk menjawab persoalan ini penulis akan memaparkan dan menganalisa pemahaman seksualitas berdasarkan etika Kristen.

\section{Metode Penelitian}

Dalam tulisan ini, penulis menggunakan pendekatan kualitatif dengan metode deskriptif. Metode deskriptif adalah pencarian fakta dengan interpretasi yang tepat (mohamad nasir). Penelitian deskriptif ini merupakan penelitian yang paling sederhana. Karena dalam penelitian ini peneliti tidak melakukan apa-apa terhadap objek atau wilayah yang ditelitih. Peneliti tidak mengubah, menambah atau mengadakan manipulasi (penipuan) terhadap objek atau wilayah penelitian. Dalam penelitian ini peneliti hanya memotret apa yang terjadi pada diri objek atau wilayah dalam hal ini pemuda-pemudi yang ada di GMIM Paulus TWM. Kemudian memaparkan apa yang terjadi dalam bentuk laporan penelitian secara tugas seperti apa adanya (suharsimi). Dalam penelitian ini penulis menggunakan pendekatan tinjauan etis Kristen terhadap masalah seksualitas yang terjadi pada pemuda-pemudi GMIM Paulus TWM.

\section{Pembahasan dan Hasil}

\section{Etika Kristen}

Kata Etika berasal dari Bahasa Yunani Ethos dan ěthos atau ta ethika dan ta ěthika. Kata Ethos artinya kebiasaan, adat, habitat, dan watak. Kata ěthos atau ta ethika dan ta èthika lebih berarti kesusilaan, perasaan batin, atau kecenderungan hati dengan mana seseorang melaksanakan suatu perbuatan ${ }^{6}$. Secara singkat dapat disimpulkan bahwa etika merupakan perilaku manusiawi yang berstandar moral, dan memberikan ketepatan nasehat tentang bagaimana bertindak dan bermoral pada situasi tertentu.

\footnotetext{
${ }^{4}$ Haryati Astuti, "Hubungan Pengetahuan Dan Sikap Terhadap Perilaku Seks Bebas," Jurnal Kebidanan Midwiferia (2017).

${ }^{5}$ Ardiansa A.T. Tucunan Yulia Ledy Tasidjawa, Grace E. C. Korompis, "HUBUNGAN ANTARA PENGETAHUAN DAN SIKAP TENTANG KESEHATAN REPRODUKSI DENGAN PERILAKU SEKSUAL PRANIKAH PADA PELAJAR DI SMP NEGERI 3 MANADO,” Jurnal KESMAS 8 (2019): 532.

${ }^{6}$ J. Verkuyl, Etika Kristen Bagian Umum (Jakarta: BPK Gunung Mulia, 2012), 1.
} 
Etika Kristen berpusatkan pada perintah Allah yang ada di dalam Alkitab, karena Alkitab adalah Firman Tuhan dan pusat dari pengajaran kekristenan ${ }^{7}$, sehingga etika Kristen adalah etika teologis yang mengacu pada ajaran dan tingkah laku dari Yesus Kristen yang diimani sebagai Anak Allah yang membawa dan mengajarkan tentang kasih Allah akan dunia ini. ${ }^{8}$ Etika Kristen juga merupakan tanggapan kepada Kasih Karunia Allah yang menyelematkan manusia, dan oleh karena itu Etika Kristen berlaku untuk seluruh kehidupan manusia. Tidak ada bagian kehidupan yang tidak perlu dibimbing oleh Tuhan. Oleh Sebab itu etika Kristen mencari kehendak Tuhan untuk setiap bagian kehidupan. ${ }^{9}$

Etika Kristen mencakup keseluruhan keseluruhan kehidupan manusia, sehingga tidak hanya dibatasi pada hal-hal rohani maupun gerejawi saja, namun juga menyangkut hal-hal yang bersifat duniawi. Etika Kristen tidak terbatas kepada kehidupan pribadi tetapi juga menyangkut perkara-perkara budaya, ekonomi, politik serta kehidupan yang menyangkut dengan pemerintahan ${ }^{10}$. Tanggung jawab orang Kristen tidak terbatas kepada orang-orang yang seiman atau segolongan, tetapi meliputi seluruh umat manusia. Mencintai Allah dan sesama seperti yang diajarkan Yesus Kristus dalam Injil juga merupakan ajaran moral dari etika Kristen. Jadi penulis dapat simpulkan bahwa etika Kristen mencakup seluruh aspek kehidupan manusia yang dilandasi pada perintah Allah yang ada di dalam Alkitab.

\section{Seksualitas Menurut Alkitab}

Seksualitas dalam pandangan Alkitab akan dibahas dalam beberapa hal yaitu: Pertama, Seksualitas adalah Ciptaan Allah, Kedua, Seksualitas adalah Anugerah Allah, Ketiga, Seksualitas bersifat Kudus, Keempat, Seksualitas dalam Pernikahan, Kelima, Seksualitas menurut Yesus Kristus, Keenam, Seksualitas menurut Rasul Paulus.

\section{Seksualitas adalah Ciptaan Allah}

Semua yang ada dalam dunia ini adalah ciptaan Allah. Allah menciptakan dunia ini dari yang tidak ada menjadi ada, dan Allah menciptakan dunia ini dengan inisiatif-Nya sendiri, dan dalam akhir penciptaan, Allah memandang semua ciptaanNya sungguh amat baik (Kej. 1:31). ${ }^{11}$ Jadi, semua yang diciptakan Allah tidak ada yang tidak baik, semuanya baik adanya, termasuk juga dengan seksualitas.

7 Yonatan Alex Arifianto, "Pentingnya Pendidikan Kristen Dalam Membangun Kerohanian Keluarga Di Masa Pandemi Covid-19," REGULA FIDEI: Jurnal Pendidikan Agama Kristen 5, no. 2 (2020): 94-106.

${ }^{8}$ Jochem Douma, Kelakuan Yang Bertanggung Jawab (Jakarta: BPK Gunung Mulia, 2007), 29.

${ }^{9}$ Malcolm Brownlee, Pengambilan Keputusan Etis Dan Faktor-Faktor Di Dalamnya (Jakarta: BPK Gunung Mulia, 2012), 29-30.

10 Sonny Zaluchu, "Sudut Pandang Etika Kristen Menyikapi Pembangkangan Sipil (Civil Disobedience)," DUNAMIS: Jurnal Teologi dan Pendidikan Kristiani (2018).

${ }^{11}$ William Dyrness, Tema-Tema Dalam Teologi Perjanjian Lama (Malang: Gandum Mas, 2013), 57. 
Seks adalah gagasan Allah, ${ }^{12}$ sehingga manusia diciptakan Allah sebagai makhluk seksual. ${ }^{13}$ Manusia diciptakan sebagai laki-laki dan perempuan dan dalam perbedaan seks itu mereka mencerminkan Allah (Kejadian. 1:27). Seksualitas diciptakan Allah demi kebaikkan, bukan kejahatan. Seksualitas adalah salah satu pemberian terindah yang oleh Allah dimaksudkan untuk memberi kesukaan besar, bukannya membawa petaka. ${ }^{14}$ Tujuan seksualitas kepada manusia ialah bukan saja untuk meneruskan jenisnya di dalam dunia, seperti umum kita dapati pada makhluk-makhluk yang lain. ${ }^{15}$ Piper menjelaskan bahwa tujuan dalam menciptakan manusia dengan kepribadian dan gairah seksual adalah untuk memastikan bahwa aka nada bahasa seksual dan gambaran seksual yang akan menunjuk kepada janji dan kesenangan-kesenangan dalam relasi Allah dengan umatNya dan relasi kita dengan Dia. ${ }^{16}$

Memiliki keturunan jua merupkan tujuan dari seksualitas, penciptaan laki-laki dan perempuan menunjukkan bahwa Allah hanya menghendaki keturunan melalui hubungan laki-laki dan perempuan. Hubungan seksual yang ditentukan Allah kepada manusia ialah hubungan heteroseksual. Hanya hubungan heteroseksual saja yang dapat menghasilkan keturunan dan dengan demikian memenuhi mandat budaya untuk "beranak cucu dan bertambah banyak" (Kej. 1:28). ${ }^{17}$ Loekmono menjelaskan, beranak cucu, dengan perintah ini, maka Allah memberikan mandat kepada manusia, laki-laki dan perempuan, untuk mengulangi ciptaan manusia melalui hubungan seksual, melalui penghamilan maka dari satu sel telur dan sel mani menjadi manusia baru. Tuhan menyerahkan itu kepada manusia, itulah yang diterima manusia dari Allah pencipta mandate ini menuntut dari manusia rasa tanggung jawab. ${ }^{18}$

Pendapat ini menjelaskan bahwa Allah memberikan mandat kepada manusia untuk berkembang biak. Secara tidak langsung Allah memerintahkan agar manusia melakukan hubungan seksual dalam pernikahan sebagai sarana mutlak dalam melaksanakan perintah Allah tersebut.

\section{Seksualitas adalah Anugerah Allah}

Anugerah merupakan pemberian Allah kepada manusia dengan cuma-cuma dan tidak ada tindakan manusia didalamnya. Tindakan Tuhan menciptakan alam semesta dan memberikannya kepada manusia adalah permulaan dari kasih karunia Tuhan. Melalui kasih karunia, Tuhan menciptakan pria dan wanita, Ia juga menciptakan kapasitas untuk

\footnotetext{
${ }^{12}$ Awasuning Manaransyah, Keluarga Bahagia (Surabaya: Revka Petra Media, 2015), 95.

${ }^{13}$ Renate Khul, Etika Seksuil (Batu: YPPII, 1988), 5.

${ }^{14}$ Awasuning Manaransyah, Keluarga Bahagia, 95.

${ }^{15}$ Abineno Ch J L, Seksualitas Dan Pendidikan Seksuil (Jakarta: BPK Gunung Mulia, 1980), 10.

16 John Piper, Seks Dan Supremasi Kristus (Surabaya: Momentum, 2011), 18-19.

${ }^{7}$ W. Andrew Hoffecker, Membangun Wawasan Dunia Kristen Volume 2 (Surabaya: Momentum,
} 2014), 487.

18 JT. Lobby Loekmono, Seksualitas Pornografi Pernikahan (Semarang: Satya Wacana, 1988), 43. 
cinta dan keintiman yang tidak pernah dialami Adam jika ia hanya seorang diri saja. Kasih karunia Tuhan menjadikan pria dan wanita bisa mengalami pengalaman seksual. ${ }^{19}$ Hubungan seksual antara suami-isteri adalah hadiah dari Allah untuk dinikmati berdua. ${ }^{20}$

Seksualitas merupakan anugerah Allah sebagai pencipta yang baik bagi manusia. Alkitab menggambarkan seksualitas sebagai anugerah Allah kepada manusia, bukan hasil karya setan, melainkan sesuatu yang wajar, yang indah, dan untuk dinikmati manusia. ${ }^{21}$ Seksualitas merupakan hal yang baik bagi manusia dan bukan suatu yang jahat (berdosa), karena seksualitas itu anugerah yang diberikan Allah kepada manusia. Verkuyl menuliskan hal demikian: nafsu birahi dan persetubuhan antara suami dan isteri oleh Alkitab tidak dipandang sebagi suatu dosa. Tetapi Alkitab memandangnya sebagai Anugerah Tuhan kepada manusia, sejak ia diciptakan. Anugerah Tuhan itu sepatutnya hanya terdapat dalam pernikahan, dan kedua orang itu tidak perlu malu karena anugerah itu. ${ }^{22}$

Jadi, anugerah yang diberikan Allah kepada manusia yang dalam hal ini adalah seksualitas, merupakan pemberian yang indah. Lewat anugerah ini manusia dimungkinkan untuk dapat berkembang biak (melanjutkan keturunan) Kejadian 1:29: Allah memberkati mereka, lalu Allah berfirman kepada mereka: "Beranakcuculah dan bertambah banyak".

Anugerah dari Tuhan ini menjadi berkat bagi manusia dan juga kebahagiaan bagi manusia. Tuhan Allah memberikan kemampuan seksualitas kepada umat manusia adalah untuk kebahagiaan bersama (Kej. 1:27-28; Ams. 5:18-19; Ams: 30:18-19; Kid. 4:10-11; Kid. $7: 1-3)^{23}$

\section{Seksualitas Bersifat Kudus}

Manusia adalah ciptaan Allah yang sempurna, agung dan suci dibandingkan dengan ciptaan lainnya karena diciptakan menurut gambar dan rupa Allah (Kej. 1:27). Hal tersebut berarti seluruh organ tubuh manusia termasuk organ seks adalah kudus. Tu'u memaparkan bahwa karena semua yang diciptakan Allah itu baik dan tidak ada satupun yang haram jika diterima dengan ucapa syukut. Sebab semuanya itu dikuduskan oleh Firman Allah dan Doa. Seks adalah bagian tubuh yang diciptakan oleh Tuhan dan dikuduskanNya. Seks bukan sesuatu yang kotor dan tabu. Seks itu baik, kudus, dan agung. ${ }^{24}$

Pendapat ini menjelaskan bahwa seksualitas diciptakan tanpa mengandung unsur dosa dan merupakan rencana Allah bagi manusia. Seksualitas bukanlah sesuatu yang memalukan, sesuatu yang harus dihindari, disangkali, atau diinginkan secara diam-diam.

Seksualitas adalah sesuatu yang indah, baik, kudus, layak dan merupakan suatu hubungan perjanjian antara seorang pria dengan isterinya. Kitab kejadian menyatakan

\footnotetext{
${ }^{19}$ Andy Stanley, The Grace Of God (Jakarta: Benaiah Books, 2013), 23-24.

${ }^{20}$ Vivian A. Soesilo, Bimbingan Pranikah Edisi 2 (Malang: SAAT, 2013), 257.

${ }^{21}$ Jonathan A. Trisna, Pernikahan Kristen (Bandung: Kalam Hidup, 1989), 90.

22 J. Verkuyl, Etika Kristen Seksuil (Jakarta: BPK Gunung Mulia, 1979), 75.

${ }^{23}$ Marulak Pasaribu, Pernikahan Dan Keluarga Kristen (Batu: YPPII, n.d.), 40.

24 Tulus Tu'u, Etika Pendidikan Seksual (Jakarta: BPK Gunung Mulia, 2002), 13.
} 
bahwa manusia diperintahkan Allah untuk berkembang biak tersebut tidak mungkin terjadi diluar pernikahan, sebab seksualitas itu suci dan hanya dapat berlangsung dalam pernikahan kudus dihadap Tuhan, karena Allah menghendaki kesucian hidup orang percaya (1 Pet. 1:15-16). ${ }^{25}$ Berkenaan dengan itu, Solbakken mengemukakanL "kehidupan seksual antara laki-laki dan perempuan dalam pernikahan bukan dosa, melainkan atas kehendak Allah. ${ }^{26}$

Seksualitas adalah kudus di dalam pernikahan, tidak kudus kalau dilakukan di luar pernikahan, bahkan Firman Tuhan menyebut sebagai perzinahan. Seksualitas kudus sesuai ciptaan Allah adalah menggunakan organ-organ seks sesuai dengan rancangan dan peruntukkannya. Pernikahan tanpa seksualitas, juga bukan suatu pernikahan yang dikehendaki Tuhan. ${ }^{27}$ Kesucian seksual berarti kebebasan dari sikap dan tindakan seks yang tidak bermoral. Dalam bahasa Yunani "Kudus" dipakai kata Hagnos yang memiliki arti "bebas dari kotoran". Kata ini berasal dari Hagios yang menandakan "kudus, murni, dan dipisahkan". ${ }^{28}$ Jadi kekudusan seksual berarti suatu kebebasan dari hal-hal yang kotor atau hal-hal yang negatif. Penyimpangan-penyimpangan seksual membuat sifat seksualitas yang adalah kudus menjadi tercemar.

\section{Seksualitas Dalam Pernikahan}

Hubungan seksualitas yang bermakna dan menyenangkan dinikmati dalam konteks pernikahan yang bahagia ketika suami isteri sama-sama merasa dihargai dan dihormati. Inilah inti rancangan Allah untuk seksualitas manusia. ${ }^{29}$ Pernikahan merupakan institusi pertama yang diciptakan Allah bagi manusia (Kej. 2:24-25). Munroe menegaskan bahwa: "Pernikahan adalah fondasi, karena di atas hubungan inilah Allah mulai membangun masyarakat. ${ }^{30}$ Pernikahan pertama di dunia ini terjadi setelah Tuhan menciptakan seorang pria, Adam dan Tuhan mengevaluasi keadaan Adam belum baik karena ia masih hidup seorang diri. Tuhan memutuskan seharusnya manusia tidak hidup sendirian dalam dunia ini, tetapi memerlukan hubungan dengan orang lain. Maka Tuhan menciptakan seorang perempuan yaitu Hawa. ${ }^{31}$ Hawa diciptakan Allah untuk menjadi penolong Adam, bukan untuk menyaingi, menekannya, mengalahkan, atau menindas. ${ }^{32}$

Dalam Kejadian. 2:24, seorang pria meninggalkan orang tuanya dan bersatu dengan isterinya sehingga mereka menjadi satu daging. Istilah "menjadi satu daging” menunjukan

\footnotetext{
${ }^{25}$ Gilbert Lumoindong dan I. Reinda Lumoindong, Pelacuran Di Balik Seragam Sekolah (Yogyakarta: ANDI, n.d.), 59-60.

${ }^{26}$ Steinar Solbakken, Eksposisi Kitab Kejadian (Batu: YPPII, 2009), 51.

${ }^{27}$ Jarot Wijanarko, Love, Sex, and Dating (Suara Pemulihan, n.d.), 8.

${ }^{28}$ June Hunt, Pastoral Konseling Alkitabiah 2 (Yogyakarta: ANDI, 2015), 102.

${ }^{29}$ Tim Clinton dan Mark Laaser, Sex and Relationship (Yogyakarta: andi, 2017), 23.

${ }^{30}$ Myle Munroe, The Purpose and Power Of Love and Marriage (Jakarta: Immanuel, 2015), 15.

${ }^{31}$ Vivian A. Soesilo, Bimbingan Pranikah Edisi 2, 3.

32 Jonathan A. Trisna, Pernikahan Kristen, 61.
} 
rencana Tuhan tentang seksualitas dalam perkawinan. Hal ini menjelaskan bahwa Tuhan melihat seksualitas sebagai media bagi suami istri untuk mencapai kesatuan. Satu daging bukanlah sekedar "menempelkan" dua orang menjadi satu, melainkan lebih merupakan "peleburan" dua unsur yang berbeda menjadi satu. ${ }^{33}$

Menjadi "satu daging" juga mengambarkan tujuan dari kegiatan seksual yang tidak hanya sebagai prokreasi (untuk memperoleh keturunan) tetapi juga psikologi (memenuhu kebutuhan emosional untuk mencapai satu hubungan kesatuan). Kesatuan menunjukan keinginan untuk mengetahui sisi paling khusus dari pasangan secara emosi, fisik dan intelektual. Ketika mereka saling memahami dengan cara yang paling khusus, mereka akan mengerti arti dari menjadi satu daging. Hubungan seksual tidak secara otomatis memberikan pengertian kesatuan. Lebih jauh lagi setiap pasangan harus memahami betul arti saling berbagi dalam hubungan suami-istri. ${ }^{34}$

Marx menjelaskan arti dari "menjadi satu daging". Untuk menciptakan suatu persekutuan yang sangat istimewa yang meliputi bidang mental dan jasmani. Untuk memperoleh keturunan dan membangun serta membina rumah tangga sendiri yang bukan dibawah pimpinan orang tua. Untuk menyalurkan dorongan-dorongan biologis (seksual) secara suci dalam suasana sejahtera (suci mencerminkan kesetiaan antara suami dan isteri). Ternyata seks tidak terlepas dari pernikahan, akan tetapi bukan menjadi disar, melainkan puncak daripada persekutuan antara Adam dan Hawa. Untuk menyatakan kasih yang murni. Untuk membantu semua pihak dalam rumah tangganya sehingga pada masingmasing anggota terbentuk akhlak dan sifat-sifat yang stabil dan kuat. Melalui pembentukan akhlak, semua pihak diharapkan makin melepaskan keakuan mereka serta mengembangkan sikap mutual care (saling memperhatikan). Untuk menjadikan rumah tangga suatu unit (lembaga) yang dapat mempengaruhi serta membahagiakan masyarakat sekelilingnya. Untuk mendidik dan membina anak-anak dengan bijaksana penuh kasih agar mereka dapat menghormati orang tua dalam arti yang sebenarnya. Untuk membina perkembangan dan pendewasaan akhlak masing-masing. ${ }^{35}$

Pernikahan merupakan tempat/wadah yang diciptakan Allah untuk mengekspresikan hubungan seksual dan pernikahan adalah satu-satunya lembaga yang direstui Allah untuk mengekspresikan diri manusia secara seksual. ${ }^{36}$ Hubungan seksual baru dimukinkan bagi orang yang sudah meninggalkan dan kemudian berdampingan dalam cinta yang terbukti, siap untuk menghayati persatuan seksual sebagai ekspresi kesatuan kasih. Tanpa perlindungan kemah nikah dan tanpa diselimuti oleh cinta, maka persetubuhan itu hampa dan tanpa persekutuan yang dihayati secara menyeluruh,

\footnotetext{
${ }^{33}$ Myle Munroe, The Purpose and Power Of Love and Marriage, 13-14.

${ }^{34} \mathrm{http} / / /$ esensiilahi.blogspot.co.id/2008/03/seks-dalam-pandangan-kristiani.html

${ }^{35}$ Dorothy I. Marx, Itu 'Kan Boleh? (Bandung: Kalam Hidup, 1997), 41.

${ }^{36}$ Awasuning Manaransyah, Keluarga Bahagia, 95.
} 
persetubuhan menjadi dangkal, dan akhirnya membosankan bahkan menjijikan. ${ }^{37}$ Persetubuhan adalah persekutuan intim antara suami isteri dalam melangsungkan keturunannya. Manusia membutuhkan keintiman. Tanpa itu jiwa manusia mati meskipun masih terus melakukan kegiatan di luar. Allah sendiri bicara dengan jelas tentang kebutuhan ini (Kej. 2:18). ${ }^{38}$

Keintiman dan kenikmatan seksual dalam pernikahan memberikan sukacita kepada suami istri. Ketika seksual dihayati oleh suami isteri, seperti yang Allah maksudkan, tidak ada yang menyamai ungkapan cinta yang menyertainya. Keintiman seksual dalam bentuknya yang paling murni merupakan berkat yang Allah sediakan bagi pasangan yang setia. $^{39}$

\section{Seksualitas Menurut Yesus Kristus}

Pengenalan dan pengertian alkitabiah yang paling komprehensif, yaitu memahami kebenaran di dalam Yesus Kristus melalui pengajaran-pengajaran-Nya. Pengajaran Yesus juga mengajarkan tentang hal seksualitas. Dalam Injil Sinoptik, Yesus memaparkan pengajaran-Nya tetnang seksualitas.

Yesus memegang teguh definisi perkawinan dalam perjanjian lama. Standar Allah atas perkawinan merupakan inti yang sama: seorang pria dan seorang wanita bersatu sampai kematian yang memisahkan. Ini bisa tampak dari kenyataan bahwa Yesus menegaskan kembali definisi perkawinan yang jelas dalam Matius 19:1-6 (bdk. Mrk. 10:112). Di sini, Yesus mengutip dari kejadian 1:27 dan 5:2. Dalam bagian ini Yesus menegaskan bahwa perkawinan didefinisikan sebagai di antara seorang pria dan seorang wanita. ${ }^{40}$ Yesus mengutip dari Kejadian 2:24: sebab itu seorang laki-laki akan meninggalkan ayahnya dan ibunya dan bersatu dengan isterinya, sehingga keduanya menjadi satu daging. Tuhan Yesus mengutip kata-kata ini sebagai Firman Allah, yang dimana melalui ketetapan Allah bahwa kedua orang itu menjadi satu. ${ }^{41}$

Istilah "satu daging" dipakai Yesus dalam pengajaran-Nya, dalam Matius 19:5 dan Markus 10:8: "satu daging" artinya persatuan yang sempurna, berarti berhubungan yang sangat dalam antara dua orang yang bersetubuh (bdk. Kej. 4:1) sehingga keduanya menjadi satu pada tingkat manusiawi yang dapat disamakan dengan kesatuan antara Kristus dengan orang Kristen (1 Kor. 6:16-17). ${ }^{42}$ Blomberg menyatakan: "one flesh" describe the interpersonal intimacy that shoukd characterize the marriage partnership and culminate in

${ }^{37}$ Volkhard Scheunemann dan Gerlinde Scheunemaan, Hidup Sebelum Dan Sesudah Nikah (Batu: YPPII, n.d.), 28.

${ }^{38}$ Ed Shaw, Same-Sex Attraction and The Church (Surabaya: Perkantas Jatim, 2016), 72-73.

${ }^{39}$ Tim Clinton dan Mark Laaser, Sex and Relationship, 16.

${ }^{40}$ Norman L. Geisler, Etika Kristen Edisi Kedua (Malang: SAAT, 2010), 317.

${ }^{41}$ F.F.Bruce, Ucapan Yesus Yang Sulit (Malang: SAAT, 2007), 51.

$42 \ldots$ _. Tafsiran Alkitab Masa Kini 3 (Jakarta: BPK Gunung Mulia, 1981), 107. 
sexual relations. ${ }^{43}$ Small menjelaskan: "God makes husbands and wives one flesh; therefore they are never to divorce". ${ }^{44}$ Yesus juga menekankan bahwa apa yang telah dipersatukan Allah, tidak boleh diceraikan oleh manusia Matius. 19:6.

Dalam beberapa hal mengenai seksualitas, Yesus mengutuknya karena telah menyeleweng dari kebenaran salah satunya ialah percabulan. Yesus mengutuk percabulan (Mat. 5:32; 15:19; Mrk. 7:21). Percabulan dipahami sebagai hubungan seksual yang disepakatai untuk dilakukan diluar pernikahan. Pelacuran, sebalikmya merupakan hubungan seksual yang disepakati dan dilakukan oleh orang yang sudah menikah. Namun tindakan yang sama bisa merupakan pelacuran bagi seseorang (yang sudah menikah) dan perzinahan bagi orang lain (yang belum nikah), kasus seperti ini bisa dilihat dalam Matius. 15:19-20, ketika Yesus berkati, "karena dari hati timbul segala pikiran yang jahat, pembunuhan, perzinahan, percabulan, pencurian, sumpah palsu dan hujat. Itulah yang menajiskan orang. Tetapi makan dengan tangan yang tidak dibasuh tidak menajiskan orang lain. Yesus melihat pencemaran moral sebagai sarana merusak jiwa. Jelaslah bahwa Yesus meanggap sumber percabulan berasal dari si jahat yang ada di dalam hati manusia dan bahwa itu merupakan sarana mencemari manusia. ${ }^{45}$ Jadi, jelaslah bahwa Yesus hanya menghendaki hubungan seksual di dalam pernikahan, bukanlah diluar pernikahan. Bila hubungan seksual dilakukan di luar pernikahan, maka hal itu disebut sebagai perzinahan, dan itu dipandang Allah sebagai kekejian.

\section{Seksualitas Menurut Rasul Paulus}

Dalam Perjanjian Baru, Rasul Paulus mengingatjan bahwa seksualitas adalah bagian integral dari pernikahan, oleh sebab itu pasangan suami-isteri harus mengaturnya dengan baik. Kepada jemaat Korintus, Paulus mengingatkan agar suami-isteri mengatur hubungan seksualitas dengan baik. Firman Tuhan menyatakan, "janganlah kamu saling menjauh, kecuali dengan persetujuan bersama untuk sementara waktu, supaya kamu mendapat kesempatan untuk berdoa. Sesudah itu hendaklah kami kembali hidup bersamasama, supaya iblis jangan menggodai kami, karena kamu tidak tahan bertara" (1 Kor. $7: 5) .{ }^{46}$

Paulus menghormati pernikahan, dan membandingkannya dengan hubungan kovenan antara Kristus dengan gereja. Ia juga mendorong pemenuhan seksual" "Hendaklah suami memenuhi kewajibannya terhadap isterinya, demikian pula isteri terhadap suaminya (1 Kor. $7: 3)^{47}$ pengajaran yang dalam akan pernikahan, diajarkan oleh Paulus kepada jemaat di Efesus. Paulus berkata, Hai isteri, tunduklah kepada suamimu

\footnotetext{
${ }^{43}$ Craig L. Blomber, The New American Commentary (America: Broadman Press, n.d.), 290.

${ }^{44}$ Dwight Hervey Small, Remarriage and God's Renewing Grace (America: Baker Book House, 1987), 97.

${ }^{45}$ Norman L. Geisler, Etika Kristen Edisi Kedua, 317.

${ }^{46}$ Marulak Pasaribu, Pernikahan Dan Keluarga Kristen, 40.

${ }^{47}$ D. A. Carson dan Jhon D. Woodbridge, God and Culture (Surabaya: Momentum, 2011), 425.
} 
seperti kepada Tuhan, karena suami adalah kepala isteri sama seperti Kristus adalah kepala Jemaat. Dialah yang menyelamatkan tubuh. Karena itu sebagaimana jemaat tunduk kepada Kristus demikian jugalaha isteri kepada suami dalam segala sesuatu. Hal ini menunjukkan sifat saling menghargai dan menghormati dalam sebuah pernikahan. ${ }^{48}$

Dalam surat-surat Paulus, ia juga menjelaskan banyak mengenai amoralitas seksualitas atau penyimpangan seksualitas. Paulus menggambarkan seksualitas yan tidak tepat sebagai bagian dari spiral murka yang menuju ke bawah dank arena ditinggalkannya Allah dalam hidup. Dalam Roma 1:24, Paulus mejelaskan, "karena itu Allah menyerahkan mereka kepada keinginan hati mereka akan kecemaran, sehingga saling mencemarkan tubuh mereka. Menurut bagian ini, Allah sudah menyingkirkan larangan-Nya dan membiarkan orang-orang ini sesuka hati, dan akibat dosa mereka dianggap sebagai penghakiman Ilahi. Mereka diserahkan pada kecemaran yang berbicara tentang seks perzinahan (2Kor. 12:21; Gal. 5:19-21; Ef. 5:3; 1 Tes. 4:7) yang dimulai dari hati, dan kemudian dilanjutkan dengan rasa malu dan menghasilkan akibat pada tubuh. ${ }^{49}$ Jadi, jelaslah bahwa Paulus menghormati hubungan Seksual hanya dalam pernihakan. Hiubungan seksual diluar pernikahan menurut Paulus ialah suatu hal yang mengakibatkan kecemaran dan dosa.

\section{Kesimpulan}

Usia muda merupakan waktu bagi seseorang untuk berkarya secara produktif. Masa ini adalah suatu masa transisi antara hidup untuk belajar tentang jati diri menuju kepada masa seorang pemuda atau pemudi yang akan mengaktualisasikan dirinya dalam berbagai aspek. Banyak hal yang akan dilakukan oleh para pemuda-pemudi untuk mengaktualisasikan kehidupan masa mudanya. Namun seiring berkembanganya zaman, banyak faktor yang sangat mempengaruhi gerenari muda dalam hubungannya dengan sesama, salah satunya adalah seksualitas.

Seksualitas merupakan hal yang indah bagi manusia karena dianugerahkan oleh Allah. Tanpa seksualitas manusia tidak bisa berhubungan intim satu dengan yang lain. Allah memperkenankan manusia untuk melakukan hubungan intim/hubungan seksual tersebut hanya dalam ikatan pernikahan. Karena dalam pernikahanlah sebuah hubungan yang intim menjadi kudus.

\footnotetext{
48 John Mark Comer, Lovelogy (Jakarta: Immanuel, 2015), 175.

${ }^{49}$ Norman L. Geisler, Etika Kristen Edisi Kedua, 319.
} 
Alfons R. Tampenawas: Tinjauan Etis Kristen Terhadap Seksualitas Di Kalangan Pemuda-Pemudi Kristen

\section{Daftar Pustaka}

Tafsiran Alkitab Masa Kini 3. Jakarta: BPK Gunung Mulia, 1981.

Abineno Ch J L. Seksualitas Dan Pendidikan Seksuil. Jakarta: BPK Gunung Mulia, 1980. Andy Stanley. The Grace Of God. Jakarta: Benaiah Books, 2013.

Arifianto, Yonatan Alex. "Pentingnya Pendidikan Kristen Dalam Membangun Kerohanian

Keluarga Di Masa Pandemi Covid-19." REGULA FIDEI: Jurnal Pendidikan Agama

Kristen 5, no. 2 (2020): 94-106.

Astuti, Haryati. "Hubungan Pengetahuan Dan Sikap Terhadap Perilaku Seks Bebas."

Jurnal Kebidanan Midwiferia (2017).

Awasuning Manaransyah. Keluarga Bahagia. Surabaya: Revka Petra Media, 2015.

Craig L. Blomber. The New American Commentary. America: Broadman Press, n.d.

D. A. Carson dan Jhon D. Woodbridge. God and Culture. Surabaya: Momentum, 2011.

Dorothy I. Marx. Itu 'Kan Boleh? Bandung: Kalam Hidup, 1997.

Dwight Hervey Small. Remarriage and God's Renewing Grace. America: Baker Book House, 1987.

Ed Shaw. Same-Sex Attraction and The Church. Surabaya: Perkantas Jatim, 2016.

F.F.Bruce. Ucapan Yesus Yang Sulit. Malang: SAAT, 2007.

Gilbert Lumoindong dan I. Reinda Lumoindong. Pelacuran Di Balik Seragam Sekolah.

Yogyakarta: ANDI, n.d.

Irawan, Andi. “Aktivitas Anak-Anak Dan Pemuda Dalam Penggunaan Internet." Cyber

Security dan Forensik Digital (2018).

J. Verkuyl. Etika Kristen Bagian Umum. Jakarta: BPK Gunung Mulia, 2012.

-. Etika Kristen Seksuil. Jakarta: BPK Gunung Mulia, 1979.

Jarot Wijanarko. Love, Sex, and Dating. Suara Pemulihan, n.d.

Jochem Douma. Kelakuan Yang Bertanggung Jawab. Jakarta: BPK Gunung Mulia, 2007.

John Mark Comer. Lovelogy. Jakarta: Immanuel, 2015.

John Piper. Seks Dan Supremasi Kristus. Surabaya: Momentum, 2011.

Jonathan A. Trisna. Pernikahan Kristen. Bandung: Kalam Hidup, 1989.

JT. Lobby Loekmono. Seksualitas Pornografi Pernikahan. Semarang: Satya Wacana, 1988.

June Hunt. Pastoral Konseling Alkitabiah 2. Yogyakarta: ANDI, 2015.

Malcolm Brownlee. Pengambilan Keputusan Etis Dan Faktor-Faktor Di Dalamnya.

Jakarta: BPK Gunung Mulia, 2012.

Marulak Pasaribu. Pernikahan Dan Keluarga Kristen. Batu: YPPII, n.d.

Myle Munroe. The Purpose and Power Of Love and Marriage. Jakarta: Immanuel, 2015.

Norman L. Geisler. Etika Kristen Edisi Kedua. Malang: SAAT, 2010.

Renate Khul. Etika Seksuil. Batu: YPPII, 1988.

Sitorus, Theresia Tiodora. "Implikasi Pembinaan Pemuda Gereja Atas Faktor-Faktor

Penyebab Kasus Hamil Di Luar Nikah.” Evangelikal: Jurnal Teologi Injili dan

Pembinaan Warga Jemaat (2020).

Steinar Solbakken. Eksposisi Kitab Kejadian. Batu: YPPII, 2009.

Tim Clinton dan Mark Laaser. Sex and Relationship. Yogyakarta: andi, 2017.

Tulus Tu'u. Etika Pendidikan Seksual. Jakarta: BPK Gunung Mulia, 2002. 
Vivian A. Soesilo. Bimbingan Pranikah Edisi 2. Malang: SAAT, 2013.

Volkhard Scheunemann dan Gerlinde Scheunemaan. Hidup Sebelum Dan Sesudah Nikah. Batu: YPPII, n.d.

W. Andrew Hoffecker. Membangun Wawasan Dunia Kristen Volume 2. Surabaya: Momentum, 2014.

William Dyrness. Tema-Tema Dalam Teologi Perjanjian Lama. Malang: Gandum Mas, 2013.

Yulia Ledy Tasidjawa, Grace E. C. Korompis, Ardiansa A.T. Tucunan. "HUBUNGAN ANTARA PENGETAHUAN DAN SIKAP TENTANG KESEHATAN

REPRODUKSI DENGAN PERILAKU SEKSUAL PRANIKAH PADA PELAJAR DI SMP NEGERI 3 MANADO.” Jurnal KESMAS 8 (2019).

Zaluchu, Sonny. "Sudut Pandang Etika Kristen Menyikapi Pembangkangan Sipil (Civil Disobedience).” DUNAMIS: Jurnal Teologi dan Pendidikan Kristiani (2018). 